\title{
5'-CpG island methylation of the LKB1/STK11 promoter and allelic loss at chromosome 19p13.3 in sporadic colorectal cancer
}

\author{
J Trojan, A Brieger, J Raedle, M Esteller, S Zeuzem
}

\begin{abstract}
Background-In patients with PeutzJeghers syndrome (PJS), causative germline mutations in the LKB1/STK11 gene on chromosome 19p13.3 have been identified. Because of the loss of heterozygosity $(\mathrm{LOH})$ at 19 p13.3 in hamartomas and the cancer susceptibility of patients with PJS, LKB1/STK11 is suggested to act as a tumour suppressor. However, the frequency of genetic and epigenetic inactivation of $L K B 1 / S T K 11$ in sporadic tumours is unclear.

Aims-To investigate the LKB1ISTK11 gene for promoter hypermethylation and allelic loss in tumour specimens of patients with sporadic colorectal cancer.

Methods-DNA from 50 consecutive paraffin embedded sporadic colorectal adenocarcinomas and corresponding normal epithelium was extracted. After bisulphite treatment, specimens were analysed for methylation of the LKB1I STK11 promoter 5'-CpG island by methylation specific polymerase chain reaction (MSP). In addition, tumours were analysed for LOH of chromosome 19p13.3. In tumours exhibiting LOH, LKB1/STK11 was sequenced.
\end{abstract}

Results-MSP was successful in 48 of 50 tumour specimens. Of those, four $(8 \%)$ demonstrated hypermethylation of the LKB1ISTK11 promoter $5^{\prime}-\mathrm{CpG}$ island. Moreover, LOH at either D19S886 or

Medizinische Klinik II, Klinikum der Johann Wolfgang

Goethe-Universität,

Frankfurt a.M.,

Germany

J Trojan

A Brieger

J Raedle

S Zeuzem

Johns Hopkins Oncology Center, Baltimore, Maryland, USA

.M. Esteller

Correspondence to: Professor Stefan Zeuzem, Medizinische Klinik II, Klinikum der Johann Wolfgang

Goethe-Universität,

Theodor-Stern-Kai 7,

D-60590 Frankfurt,

Germany. Email

Zeuzem@em.uni-frankfurt.de

Accepted for publication

11 January 2000

Keywords: sporadic colorectal adenocarcinoma; tumour suppressor genes; protein-serine-threonine kinase gene $L K B 1 / S T K 11$; promoter hypermethylation; loss of heterozygosity

Several tumour suppressor genes, which are inactivated through germline mutations in the most commonly inherited colorectal cancer susceptibility syndromes, such as the $A P C$ gene in familial adenomatous polyposis and the DNA mismatch repair genes $M S H 2, M L H 1$, PMS1, PMS2, and MSH6/GTBP in hereditary non-polyposis colorectal cancer, are involved in the development and progression of sporadic colorectal cancer. ${ }^{12}$ Moreover, loss of transcription of tumour suppressor genes, including p16, MGMT, and $M L H 1$, by epigenetic changes such as hypermethylation of 5 '-CpG islands in the promoter region have been demonstrated in colorectal cancer. ${ }^{34}$

Recently, a gene mutation in patients with Peutz-Jeghers syndrome (PJS), an autosomal dominant disorder characterised by mucocutaneous pigmentation, intestinal hamartomas, and an increased risk of cancers of the gastrointestinal tract, breast, testis, and ovary, has been identified by genetic linkage studies and positional cloning. ${ }^{56}$ This gene, named $L K B 1$, $S T K 11$, or $L K B 1 / S T K 11$, is located on chromosome $19 \mathrm{p} 13.3^{7}$ and encodes for a serinethreonine kinase, a human homologue of Xenopus early embryonic kinase $1 .{ }^{8} \mathrm{LKB} 1 /$ STK11 is suggested to act as a tumour suppressor gene in PJS because hamartoma formation in PJS patients with inactivating $L K B 1 / S T K 11$ germline mutations is associated with somatic loss of the wild-type LKB1/ STK11 allele. ${ }^{79}{ }^{10}$ The development of cancer in patients with PJS does not exclusively arise in association with hamartomas ${ }^{11}$ but dysplasia with consecutive neoplastic transformation within hamartomatous polyps accounts for at least some malignancies in this syndrome. ${ }^{12} 13$ In contrast with the pathogenesis of sporadic colorectal cancer, frequently involving $A P C$, $K$-ras, $D C C, M C C$, and $p 53,{ }^{12}{ }^{14}$ the molecular mechanisms leading to cancer in patients with PJS remain unclear. Because patients with PJS are at increased risk of colorectal cancer, LKB1/STK11 may also be a target during the carcinogenesis of sporadic colorectal cancer. Although some reports revealed a low frequency of somatic mutations of the LKB1/ STK11 gene in colorectal tumour specimens, ${ }^{15-17}$ conflicting data were most recently reported by Dong and colleagues. ${ }^{18}$ This group identified somatic LKB1/STK11 mutations in one third of left sided colorectal cancers and in two colonic adenomas. In con-
Abbreviations used in this paper: $L K B 1 / S T K 11$, serine-threonine kinase gene $L K B 1 / S T K 11$; LOH, loss of heterozygosity; PJS, Peutz-Jeghers syndrome; UICC, International Union Against Cancer; PCR, polymerase chain reaction; MSP, methylation specific polymerase chain reaction; bp, base pairs. 
trast, LKB1/STK11 promoter hypermethylation leading to transcriptional inactivation was found in a few cancer cell lines and a subset of primary tumours. ${ }^{19}$

To further analyse the role of LKB1/STK11 on chromosome 19p13.3 in the pathogenesis of sporadic colorectal cancer, we investigated the frequency of genetic and epigenetic alterations at the LKB1/STK11 gene locus in tumour specimens from 50 consecutive patients with colorectal cancer.

\section{Methods}

TUMOUR SPECIMENS

Tumour specimens from 50 consecutive patients (21 females, 29 males) with sporadic colorectal adenocarcinoma (International Union Against Cancer (UICC) stage I, $\mathrm{n}=9$; stage II, $n=10$; stage III, $n=17$; stage IV, $n=14$ ) were analysed. At the time of diagnosis, patients were aged 35-95 years (mean 55 (17) years). In 38 patients tumours were left sided (descending colon, sigmoid colon, or rectum) whereas 12 patients had a right sided colon carcinoma (transverse colon, ascending colon, or caecum). Histologically, two tumours were characterised as well differentiated, 39 as moderately differentiated, six as poorly differentiated, and three as undifferentiated. None of the patients had a family history of PJS, familial adenomatous polyposis, or hereditary nonpolyposis colorectal cancer and none of the tumours exhibited microsatellite instability (data not shown).

For molecular analysis, representative $5 \mu \mathrm{m}$ sections of paraffin embedded normal and tumour tissue were mounted onto slides and dried for 60 minutes at $50^{\circ} \mathrm{C}$. After microdissection DNA was extracted using the QIAamp DNA mini kit (Qiagen, Hilden, Germany).

METHYLATION SPECIFIC PCR OF THE LKB1/STK11 PROMOTER

Analysis of methylation patterns within the 5'-CpG island of the LKB1/STK11 gene were carried out using chemical modification of $1 \mu \mathrm{g}$ of genomic DNA from colorectal cancer specimens with sodium bisulphite and methylation specific polymerase chain reaction (MSP) using sense primers for methylated and unmethylated polymerase chain reactions (PCR) beginning at base pairs (bp) 15 and 17, respectively, from GeneBank sequence AF 035625, as previously described. ${ }^{19}$ Primers used for the

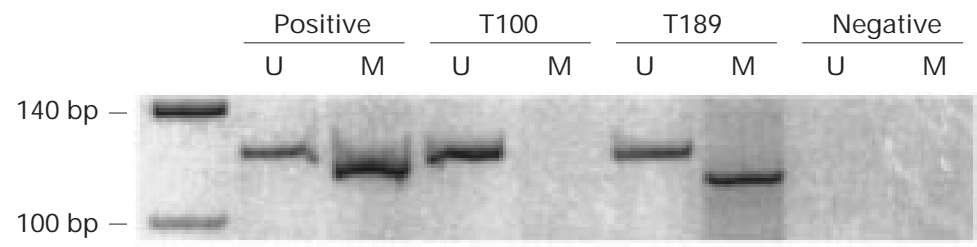

Figure 1 Methylation specific polymerase chain reaction (PCR) of the LKB1/STK11 promoter 5'-CpG island in sporadic colorectal cancer. In the left lane the $140 \mathrm{bp}$ and $100 \mathrm{bp}$ bands of a molecular weight standard are shown. The presence of a visible PCR product in those lanes marked U indicates unmethylated LKB1/STK11 promoter 5'-CpG islands; a visible PCR product in those lanes marked $M$ indicates the presence of methylated LKB1/STK11 promoter 5'-CpG islands. Corresponding lanes are: positive controls for PCR reactions (for the unmethylated reaction DNA extracted from the colorectal cancer cell line HT29 and for the methylated reaction from the colorectal cancer cell line H6), primary colorectal cancers (T100 and T189), and negative controls for PCR reactions. unmethylated reaction were 5'-GGATGA AGTTGATTTTGATTGGGTT-3' (sense) and 5'-ACCCAATACAAAATCTACAAA CC AACA-3' (antisense) and for the methylated reaction 5'-ACGAAGTTGATTTTGA TCGGGTC-3' (sense) and 5'-CGATAC AAAATCTACGAACCGACG-3' (antisense). PCR was carried out in a final volume of $50 \mu \mathrm{l}$ containing $3.5 \mathrm{mM}$ magnesium chloride, 15 $\mathrm{mM}$ ammonium sulphate, $60 \mathrm{mM}$ Tris $\mathrm{HCl}$ (pH 8.5), $250 \mu \mathrm{M}$ each of dATP, dTTP, dCTP, and dGTP (Invitrogen, Leek, Netherlands), $0.1 \mu \mathrm{M}$ forward and reverse primers (Biospring, Frankfurt, Germany), and 2.5 U of AmpliTaq Gold DNA polymerase (Perkin Elmer, Weiterstadt, Germany) for 10 minutes at $95^{\circ} \mathrm{C}$ followed by 55 cycles of 30 seconds at $95^{\circ} \mathrm{C}, 30$ seconds at $55^{\circ} \mathrm{C}$, one minute at $72^{\circ} \mathrm{C}$, and a final extension of 10 minutes at $72^{\circ} \mathrm{C}$. PCR products were electrophoresed on nondenaturating polyacrylamide gels $(8 \%)$ and visualised by silver staining.

LOSS OF HETEROZYGOSITY ANALYSIS OF 19p13.3 After PCR amplification of DNA extracted from normal and tumour tissue the microsatellite markers D19S886, located telomeric to the LKB1/STK11 gene locus on chromosome 19p13.3, and D19S878, located 6.5 cM proximal to D19S886, ${ }^{20}$ were analysed for loss of heterozygosity $(\mathrm{LOH})$. Primer sequences for D19S886 were 5'-TGGATCTACACTCC GGC-3' (sense) and 5'-ATTTTACTGGC TGGCACTTG-3' (antisense), and for D19S878 were 5'-GCCTGGGCGACA GAGAAT-3' (sense) and 5'-GGTTGC CCGCAGAGTG-3' (antisense). PCR was carried out in a final volume of $50 \mu \mathrm{l}$ containing $2.5 \mathrm{mM}$ magnesium chloride, $15 \mathrm{mM}$ ammonium sulphate, $60 \mathrm{mM}$ Tris $\mathrm{HCl}(\mathrm{pH} 8.5), 250$ $\mu \mathrm{M}$ each of dATP, dTTP, dCTP, and dGTP (Invitrogen), $0.1 \mu \mathrm{M}$ of 6-carboxy-fluorescein labelled forward and $0.1 \mu \mathrm{M}$ reverse primers (Biospring), and 2.5 U of AmpliTaq Gold DNA polymerase (Perkin Elmer) for 10 minutes at $95^{\circ} \mathrm{C}$ followed by 45 cycles of 30 seconds at $95^{\circ} \mathrm{C}, 30$ seconds at $55^{\circ} \mathrm{C}$, one minute at $72^{\circ} \mathrm{C}$, and a final extension of 10 minutes at $72^{\circ} \mathrm{C}$. Electrophoresis was carried out in an ABI 310 DNA sequencer (Perkin Elmer) and the final analysis was performed using the Gene Scan 2.1 software (Perkin Elmer).

GENOMIC PCR AMPLIFICATION AND SEQUENCE ANALYSIS OF THE LKB1/STK11 GENE

Genomic PCR amplification of the coding region of the LKB1/STK11 gene was carried out using published primer sets. ${ }^{5}{ }^{15}$ PCR reactions were carried out in a total volume of $50 \mu \mathrm{l}$, consisting of 1.5-3.5 mM magnesium chloride, $15 \mathrm{mmol} / \mathrm{l}$ ammonium sulphate, $60 \mathrm{mM}$ Tris $\mathrm{HCl}(\mathrm{pH} 8.5), 250 \mu \mathrm{M}$ each of dATP, dTTP, dCTP, and dGTP (Invitrogen), $1 \mu \mathrm{M}$ of forward and reverse primers (Biospring), and 2.5 U of AmpliTaq Gold DNA polymerase (Perkin Elmer). The following amplification conditions were used: 12 minutes at $95^{\circ} \mathrm{C} ; 40$ cycles of 45 seconds at $95^{\circ} \mathrm{C}$, one minute annealing at $55^{\circ} \mathrm{C}$, and two minutes at $72^{\circ} \mathrm{C}$; and a final extension of 10 minutes at $72^{\circ} \mathrm{C}$. 

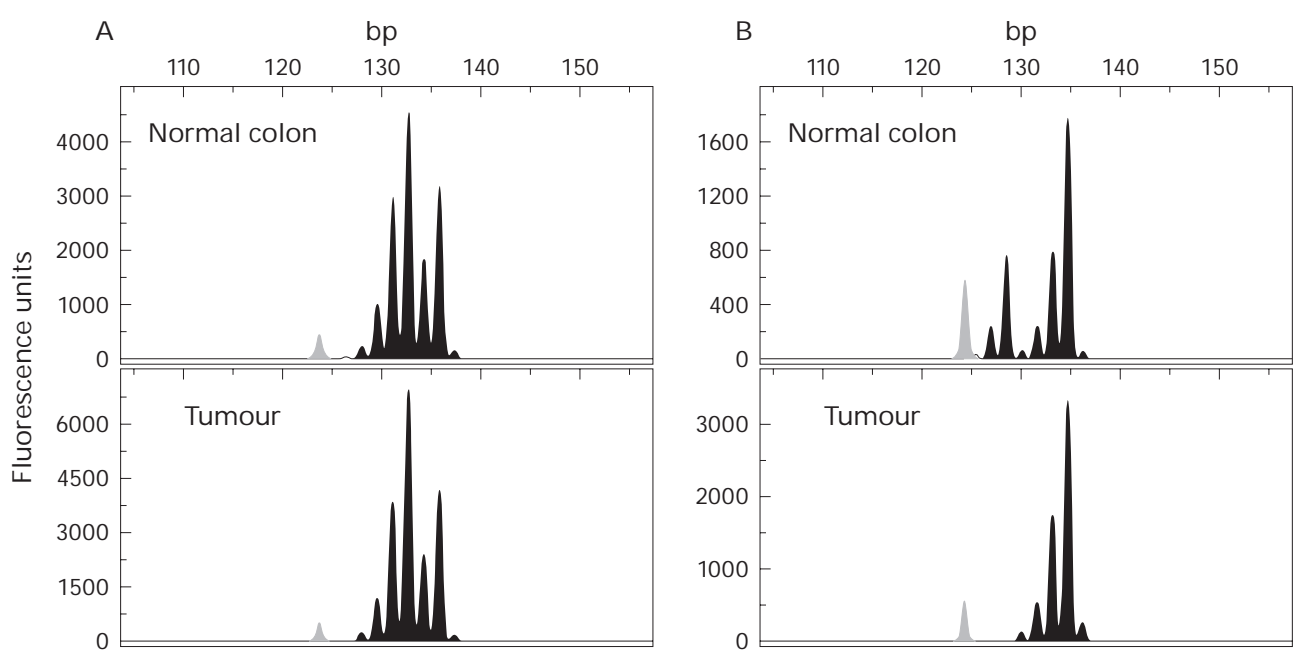

Figure 2 Fluorescent analysis of the microsatellite marker D19S878 (centromeric to the LKB1/STK11 gene locus) on chromosome 19p13.3. The $123 \mathrm{bp}$ peak of the size standard is plotted in light grey in all electrophoretic profiles. The polymerase chain reaction (PCR) products of normal colon tissue (upper panels) and corresponding tumour tissue (lower panels) in patient No 31 (A) and No 3 (B) with sporadic colorectal adenocarcinoma were electrophoretically analysed on an automated ABI 310 DNA sequencer (Perkin Elmer). (A) Tumour without allelic loss at D19S878. (B) Tumour exhibiting loss of the $127 \mathrm{bp}$ allele of D19S878 whereas the $134 \mathrm{bp}$ allele is conserved.

PCR products of the $L K B 1 / S T K 11$ gene were purified and bidirectionally sequenced according to the instructions of the Dye Deoxy Terminator protocol (Perkin Elmer). Automated sequence analysis was carried out on an ABI 310 DNA sequencer (Perkin Elmer).

\section{Results}

LKB1/STK115'-CpG ISLAND METHYLATION Methylation specific PCR (MSP) for analysis of the $L K B 1 / S T K 11$ promoter $5^{\prime}-\mathrm{CpG}$ island was carried out with DNA extracted from 50 paraffin embedded colorectal cancer specimens. DNA extracted from the colorectal cancer cell lines HT29 and H6 served as positive controls for the unmethylated and methylated reactions, respectively (fig 1 ). In two specimens there was insufficient DNA for MSP. In the remaining 48 tumour specimens MSP was successful. Of those, four (8\%) tumours demonstrated both methylated and unmethylated $L K B 1 / S T K 11$ promoter 5'-CpG islands whereas the remaining 44 specimens displayed only unmethylated promoter islands. The presence of methylated $L K B 1 / S T K 11$ promoter 5'-CpG islands was not associated with tumour stage, location, or histological grading.

LOH ANALYSIS OF $19 \mathrm{p} 13.3$

To investigate the LKB1/STK11 gene locus in sporadic colorectal cancer for allelic loss at chromosome $19 \mathrm{p} 13.3$, we analysed paraffin embedded normal DNA and corresponding tumour DNA. Thirty eight of 50 tumour specimens were considered informative for at least one microsatellite marker. $\mathrm{LOH}$ at either D19S886 or D19S878 was observed in five of $38(13 \%)$ informative sporadic colorectal cancer specimens. Allelic loss at D19S878 occurred in four tumours (fig 2) whereas one tumour exhibited LOH at D19S886. Three of five tumours with $\mathrm{LOH}$ at $19 \mathrm{p} 13.3$ were classified as UICC stage IV whereas the other two were UICC stage III tumours. Four of the five tumours with $\mathrm{LOH}$ at $19 \mathrm{p} 13.3$ were located in the sigmoid colon or rectum. There was no association between $\mathrm{LOH}$ and histological grade. None of the tumours displaying LKB1/STK11 promoter 5'-CpG island hypermethylation was found to exhibit LOH at chromosome 19p13.3.

LKB1/STK11 SEQUENCE ANALYSIS

To test if the LKB1/STK11 gene in five tumours exhibiting $\mathrm{LOH}$ at $19 \mathrm{p} 13.3$ was inactivated because of a somatic mutation of the remaining allele, genomic sequencing of the coding region and splicing sites of the complete $L K B 1 / S T K 11$ gene was performed. In none of those tumours was a somatic $L K B 1 / S T K 11$ mutation detected, suggesting that $\mathrm{LOH}$ occurred independently of mutational events of the remaining $L K B 1 / S T K 11$ allele.

\section{Discussion}

Inactivating $L K B 1 / S T K 11$ germline mutations in combination with loss of the wild-type allele are responsible for the development of hamartomatous polyps in patients with Peutz-Jeghers syndrome (PJS)..$^{7}{ }^{10}$ To address the pathogenesis of intestinal hamartomas and adenocarcinomas, Gruber et al studied specimens of PJS patients carrying a heterozygote $L K B 1 / S T K 11$ germline mutation. ${ }^{9}$ Their data further supported the hypothesis that hamartomas and adenocarcinomas in patients with PJS develop through allelic loss of the wild-type LKB1/ STK11 allele whereas alterations of genes affected in the majority of sporadic colorectal carcinomas ( $A P C, \mathrm{~K}$-ras, p53) occur at later stages of tumour progression. Thus LKB1/ STK11 is considered a tumour suppressor gene in PJS.

Recently, promoter hypermethylation was established as a new concept of tumour suppressor gene inactivation. ${ }^{321}$ In particular, hypermethylation of 5'-CpG islands, usually located in the promoter region of widely expressed genes, has been shown to correlate with decreased or loss of expression. In this study using the published primer sets for the 
5'-CpG island of the $L K B 1 / S T K 11$ promoter, we showed the feasibility of $L K B 1 / S T K 11$ promoter methylation analysis in a large series of paraffin embedded colorectal cancer specimens, and confirmed the data of Esteller et al who found one of 43 primary colorectal cancer specimens methylated at the LKB1/STK11 promoter. $^{19}$

Furthermore, allelic loss at chromosome 19 p13.3 was analysed. Using microsatellite markers flanking the $L K B 1 / S T K 11$ gene locus ${ }^{20}$ we found $\mathrm{LOH}$ on chromosome $19 \mathrm{p} 13.3$ in five of 38 (13\%) informative tumour specimens of patients with sporadic colorectal cancer. To investigate if allelic loss at 19p13.3 occurred in combination with alterations of the remaining allele-according to a "two-hit" inactivation mechanism characteristic of tumour suppressor genes ${ }^{22}$-we sequenced the entire coding region of the $L K B 1 / S T K 11$ gene in all five tumours with $\mathrm{LOH}$ at $19 \mathrm{p} 13.3$. No somatic LKB1/STK11 gene mutations were found in these tumours. Our data are in accordance with the studies of Aviziente et al and Resta et al who also did not detect somatic LKB1/STK11 gene mutations in 13 and 10 sporadic colorectal adenocarcinomas with $\mathrm{LOH}$ at $19 \mathrm{p} 13.3$, respectively. ${ }^{15}{ }^{17}$ The data are further confirmed by Wang et al who could not detect any bandshifts in the nine exons of the LKB1/STK11 gene in 72 sporadic colorectal adenocarcinomas by single strand conformational polymorphism. ${ }^{16}$ In contrast, Dong et al detected somatic LKB1/STK11 gene mutations in $7 / 23(30 \%)$ Korean patients with invasive adenocarcinomas of the sigmoid colon or rectum. Allelic loss at chromosome 19p13.3 was present in six of seven cancers with a somatic LKB1/STK11 mutation. ${ }^{18}$ Moreover, this study reported $L K B 1 / S T K 11$ mutations in two of $12(17 \%)$ colonic adenomas with high grade dysplasia. Eight of nine mutations reported by Dong et al were missense whereas only one was a frameshift mutation causing a premature stop codon. It remains unclear if these geographical differences in $L K B 1 / S T K 11$ mutation frequency during colorectal tumorigenesis are caused by environmental factors such as dietary exposure to certain carcinogens.

To date, absence or a low frequency of somatic LKB1/STK11 mutations has been reported in sporadic breast cancer $(0 / 62),{ }^{23}$ testicular tumour $(1 / 28),{ }^{15}$ malignant melanoma $(4 / 85),{ }^{24-26}$ biliary $(1 / 16)$, periampullary $(0 / 19),{ }^{27}$ and pancreatic adenocarcinoma $(5 / 112),{ }^{24} 27$ carcinoma of the stomach $(3 / 36),{ }^{28}$ carcinoma of the uterine cervix $(1 / 26)$, ovarian adenocarcinoma $(0 / 37),{ }^{29}$ ovarian granulosa cell tumour $(1 / 24),{ }^{24}{ }^{29}$ renal cell cancer $(0 / 19)$, lung cancer $(1 / 28)$, and sarcoma $(0 / 24) .{ }^{24}$ In contrast with the predominance of truncating frameshift germline LKB1/STK11 mutations in patients with PJS, the vast majority of somatic LKB1/STK11 mutations detected so far are missense mutations. Recently, Mehenni et al and Ylikorkala et al reported functional in vitro assays to assess the effects of LKB1/STK11 germline mutations detected in patients with PJS. ${ }^{30}$ Mutant LKB1/STK11 proteins resulting from frameshift or missense LKB1/STK11 mutations, including a single amino acid change (G163D) reported in a sporadic testicular tumour, resulted in severely impaired or complete loss of kinase activity. Nevertheless, the consequences of somatic missense LKB1/STK11 mutations have not yet been studied in vivo.

In summary, promoter hypermethylation and allelic loss of the $L K B 1 / S T K 11$ gene are rare events in sporadic colorectal cancer in Caucasian patients. $\mathrm{LOH}$ at $19 \mathrm{p} 13.3$ is associated with advanced tumour stage and left sided location but not with $L K B 1 / S T K 11$ promoter hypermethylation or somatic mutation. Because epigenetic or genetic inactivation of $L K B 1 / S T K 11$ in sporadic colorectal cancer is a rare event, it is unlikely that $L K B 1 / S T K 11$ alterations are key players in the molecular pathogenesis of this tumour entity. The authors thank Dr J G Herman, Johns Hopkins Oncology
Center, Baltimore, Maryland, USA, for critical review of the manuscript, Dr G Herrmann, Senckenbergisches Zentrum der Pathologie, Klinikum der Johann Wolfgang Goethe-Universität, Pathologie, Klinikum der Johann Wolfgang Goethe-Universität, Frankfurt, Germany, for microdissection of colorectal cancer
specimens, and N Weber for technical assistance. This work was specimens, and $\mathrm{N}$ Weber for technical assistance. This work was
supported in part by a grant from the Arthur and Margarete supported in part by a grant from the
Ebert foundation, Frankfurt, Germany.

1 Kinzler KW, Vogelstein B. Lessons from hereditary colorectal cancer. Cell 1996;87:159-70.

2 Lynch HT, Lynch JF. Genetics of colonic cancer. Digestion 1998;59:481-92.

3 Herman JG. Hypermethylation of tumor suppressor genes in cancer. Semin Cancer Biol 1999;9:359-67.

4 Esteller M, Hamilton SR, Burger PC, et al. Inactivation of the DNA repair gene O6-methylguanine-DNA methyltransferase by promoter hypermethylation is a common event in primary human neoplasia. Cancer Res 1999;59: 793-7.

5 Hemminki A, Markie D, Tomlinson IP, et al. A serine/ threonine kinase gene defective in Peutz-Jeghers syndrome. Nature 1998;391:184-7.

6 Jenne DE, Reimann H, Nezu J, et al. Peutz-Jeghers syndrome is caused by mutations in a novel serine threonine kinase. Nat Genet 1998;18:38-44.

7 Hemminki A, Tomlinson I, Markie D, et al. Localization of a susceptibility locus for Peutz-Jeghers syndrome to $19 p$ using comparative genomic hybridization and targeted linkage analysis. Nat Genet 1997;15:87-90.

$8 \mathrm{Su}$ JY, Erikson E, Maller J. Cloning and characterization of a novel serine/threonine protein kinase expressed in early Xenopus embryos. F Biol Chem 1996;271:14430-7.

9 Gruber SB, Entius MM, Petersen GM, et al. Pathogenesis of adenocarcinoma in Peutz-Jeghers syndrome. Cancer Res adenocarcinoma in

10 Trojan J, Brieger A, Raedle J, et al. Peutz-Jeghers syndrome: molecular analysis of a three-generation kindred with a novel defect in the serine threonine kinase gene STK11. Am f Gastroenterol 1999;94:257-61.

11 Giardiello FM, Welsh SB, Hamilton SR, et al. Increased risk of cancer in the Peutz-Jeghers syndrome. $N$ Engl $\mathcal{F} \mathrm{Med}$ 1987;316:1511-14.

12 Spigelman AD, Murday V, Phillips RKS. Cancer and the Peutz-Jeghers syndrome. Gut 1989;30:1588-90.

13 Boardman LA, Thibodeau SN, Schaid DJ, et al. Increased risk for cancer in patients with the Peutz-Jeghers syndrome. Ann Intern Med 1998;128:896-9.

14 Vogelstein B, Fearon ER, Hamilton SR, et al. Genetic alterations during colorectal-tumor development. $N$ Engl $\mathscr{f} \mathrm{Med}$ 1988;319:525-32.

15 Aviziente E, Roth S, Loukola A, et al. Somatic mutations in $\mathrm{LKB} 1$ are rare in sporadic colorectal and testicular tumors. Cancer Res 1998;58:2087-90.

16 Wang ZJ, Taylor F, Churchman M, et al. Genetic pathways of colorectal carcinogenesis rarely involve the PTEN and LKB1 genes outside the inherited hamartoma syndromes. Am F Pathol 1998;153:363-6.

17 Resta N, Simone C, Mareni C, et al. STK11 mutations in Peutz-Jeghers syndrome and sporadic colon cancer. Cancer Res 1998;58:4799-801.

18 Dong SM, Kim KM, Kim SY, et al. Frequent somatic mutations in serine/threonine kinase 11/Peutz-Jeghers syndrome gene in left-sided colon cancer. Cancer Res 1998;58:378790.

19 Esteller M, Avizienyte E, Corn PG, et al. Epigenetic inactivation of LKB1 in primary tumors associated with the veutz-Jeghers syndrome. Oncogene 2000;19:164-8.

20 Amos CI, Bali D, Thiel TJ, et al. Fine mapping of a genetic locus for Peutz-Jeghers syndrome on chromosome 19p. Cancer Res 1997;57:3653-6. 
21 Jones PA, Laird PW. Cancer epigenetics comes of age. Nat Genet 1999;21:163-7.

22 Knudson AG. Antioncogenes and human cancer. Proc Natl Acad Sci USA 1993;90:10914-21.

23 Bignell GR, Barfoot R, Seal S, et al. Low frequency of somatic mutations in the LKB1/Peutz-Jeghers syndrome gene in sporadic breast cancer. Cancer Res 1998;58:1384-6.

24 Avizienyte E, Loukola A, Roth S, et al. LKB1 somatic mutations in sporadic tumors. Am f Pathol 1999;154:677-81.

25 Guldberg P, thor Straten P, Ahrenkiel V, et al. Somatic mutation of the Peutz-Jeghers syndrome gene, LKB1/ STK11, in malignant melanoma. Oncogene 1999;18:177780.

26 Rowan A, Bataille V, MacKie R, et al. Somatic mutations in the Peutz-Jeghers (LKB1/STK11) gene in sporadic malignant melanomas. F Invest Dermatol 1999;112:509-11.

$27 \mathrm{Su}$ GH, Hruban RH, Bansal RK, et al. Germline and somatic mutations of the STK11/LKB1 Peutz-Jeghers gene in pancreatic and biliary cancers. Am f Pathol 1999;154: $1835-40$.

28 Park WS, Moon YW, Yang YM, et al. Mutations of the STK11 gene in sporadic gastric carcinoma. Int $\mathcal{f}$ Oncol 1998;13:601-4.

29 Wang ZJ, Churchman M, Campbell IG, et al. Allele loss and mutation screen at the Peutz-Jeghers (LKB1) locus 19p13.3) in sporadic ovarian tumours. Br f Cancer 1999; 80:70-2.

30 Mehenni H, Gehrig C, Nezu J, et al. Loss of LKB1 kinase activity in Peutz-Jeghers syndrome, and evidence for allelic and locus heterogeneity. Am F Hum Genet 1998;63:164150.

31 Ylikorkala A, Avizienyte E, Tomlinson IP, et al. Mutations and impaired function of LKB1 in familial and noncancer. Hum Mol Genet 1999;8:45-51. 